\title{
Bladder and vaginal transitional cell carcinoma: A case report
}

\author{
FOUAD AOUN, HAMPIG RAPHAEL KOURIE, ELIE EL RASSY and ROLAND VAN VELTHOVEN
}

Department of Urology, Jules Bordet Institute, Université Libre de Bruxelles, Brussels 1000, Belgium

Received January 16, 2015; Accepted November 20, 2015

DOI: $10.3892 / 01.2016 .4894$

\begin{abstract}
The involvement of the female genital tract in transitional cell carcinoma (TCC) has not been fully elucidated in women, although involvement is usually associated with a poor prognosis. The vagina, in particular, is considered to be the most commonly affected gynecological organ, with an incidence of $4 \%$ of total TCC cases. The pathogenesis of vaginal TCC is challenging to determine, although it is essential for the adequate management of the tumor and to determine the appropriate treatment. The present study reports a case of bladder TCC and metachronous vaginal TCC. The patient had a history of high risk non muscle invasive bladder cancer treated by BCG and presented with a recurrent carcinoma in situ. A novel cycle of BCG was initiated but the patient had a persistent disease and a palpable mass on bimanual examination. Radical anterior pelvectomy and bilateral pelvic and inguinal lymph node dissection was performed revealing the presence of TCC of the bladder neck and the invasion into the anterior vaginal wall. The differences between local vaginal invasion and the metastatic spread from a primary bladder TCC, the occurrence of a second primary vaginal tumor and the direct implantation of TCC via urine that contains transitional cancer cells were reviewed and analyzed. Finally, a management plan was determined.
\end{abstract}

\section{Introduction}

Transitional cell carcinoma (TCC) of the urinary bladder is the ninth most common cancer in women in the USA. The American Cancer Society estimated that $\sim 4,410$ women succumbed to TCC in 2014 (1). The incidence of the disease in women is increasing, but remains 3-4 times lower compared with the incidence in men (2). However, the bladder cancer-associated mortality rate is greater in women (2). The greater mortality rate is partially attributable to delays in the diagnosis of TCC, which leads to an increased stage at presentation (2). In addition, the association and effect of

Correspondence to: Dr Fouad Aoun, Department of Urology, Jules Bordet Institute, Université Libre de Bruxelles, 121 Boulevard de Waterloo, Brussels 1000, Belgium

E-mail: fouad.aoun@bordet.be

Key words: bladder cancer, vaginal cancer, transitional cell carcinoma, metastasis, second primary, local invasion gender on bladder TTC incidence, staging, prognosis and survival are poorly understood (3). The involvement of the female genital tract by TCC is another unsolved problem, and is usually associated with a poor prognosis (3). The vagina is considered to be the most commonly affected gynecological organ, with a TCC incidence of $\sim 4 \%$ of the total TCC cases $(4,5)$. The pathogenesis of vaginal TCC is challenging to determine. In the present study, a case of bladder TCC with metachronous vaginal TCC was discussed. The differences between local vaginal invasion and the metastatic spread from a primary bladder TCC, the occurrence of a second primary vaginal tumor and the direct implantation of TCC via urine that contains transitional cancer cells were reviewed and analyzed.

\section{Case report}

A 62-year-old female patient presented to the Department of Urology (Jules Bordet Institute, Université Libre de Bruxelles, Brussels, Belgium) in February 2013. The patient possessed a previous medical history of non-muscle invasive transitional bladder carcinoma, which was diagnosed in September 2009 and treated by a complete transurethral resection, and 3 years of maintenance therapy by endovesical Bacille Calmette-Guerin (BCG) instillation. The initial pathology demonstrated a diffuse carcinoma in situ (CIS). A follow-up cystoscopy in 2013 revealed recurrent CIS and no evidence of muscle invasion. The attendees of a multidisciplinary oncological meeting decided to administer a novel cycle of BCG instead of a radical cystectomy and bilateral pelvic lymph node dissection. A thoraco-abdominopelvic computed tomography scan revealed irregular thickening of the bladder wall and no evidence of regional or distant metastasis. The patient opted to be treated with a novel cycle of BCG. Following the induction therapy (6 weekly instillations), a flexible cystoscopy revealed the persistence of bladder CIS and a palpable mass through the anterior vaginal wall. A radical anterior pelvectomy and bilateral pelvic and inguinal lymph node dissection was performed. A definitive pathological examination confirmed the diagnosis of TCC of the bladder neck and the invasion into the anterior vaginal wall, and diffuse bladder CIS. The malignant infiltration of pelvic and inguinal lymph nodes was also evident. The surgical margins were negative. Adjuvant chemotherapy, consisting of gemcitabine and cisplatin, was initiated. The patient presented 6 months later with a vaginal mass and the absence of distant metastasis. A biopsy of the mass demonstrated atypical cells 
that expressed cytokeratin 34bE12, GATA 3 and protein P16, which are consistent with a high-grade invasive urothelial carcinoma.

All procedures used were in accordance with the ethical standards of the Institute Jules Bordet Ethics Review Committee (Brussels, Belgium) and the Declaration of Helsinki, as revised in 2000 (6). Informed consent for inclusion in the present study was obtained from the patient.

\section{Discussion}

The presence of TCC in the vaginal wall is an uncommon heterogeneous entity (3). Due to the location of the anterior wall of the vagina, the direct spread from a muscle-invasive transitional bladder cancer is not unusual in advanced and metastatic bladder cancer $(4,7)$. The direct spread confers a poor prognosis due to the advanced stage of the disease (8). However, few cases of vaginal TCC that occur synchronously or metachronously with non-muscle invasive TCC of the urinary tract have been described $(9,10)$. In addition, the extremely rare entity of primary vaginal TCC in the absence of a urinary tract tumor has also been reported (11-13). The pathogeneses of these variable clinical scenarios appear to be varied; however, the small number of cases in each group renders establishing the pathogenesis challenging. Recognizing and differentiating these entities is therefore critical in order to stratify the malignant behavior and distinguish the treatment and prognosis for the diseases.

The common embryological origin of the vagina and the urinary tract may explain the metaplasia of the vaginal squamous epithelium to TCC $(14,15)$. Two hypotheses exist to explain the pathogenesis of primary vaginal TCC. The first hypothesis, 'true multifocality', was suggested by Jendresen et al (14) and postulates that transitional cell neoplasms are derived from a common vaginal stem cell line with pluripotent capacity. This hypothesis involves the presence of various foci of cancer in the urogenital tract, and may explain primary transitional carcinoma of the vagina and its association with TCC in the urinary tract (14). The second hypothesis, proposed by Singer et al (15), emphasizes the seeding phenomenon that involves the pagetoid spread of cancer cells to distant mucosa. The majority of these tumors occur in the cervix (12). Histologically, these tumors are composed of mixed squamous and TCC cells (12). At present, only 3 reported cases were diagnosed with TCC of the vagina without a prior history of TCC in the urinary tract $(12,13)$. Pure TCC, similar to TCC of the urinary system, is extremely rare. Immunohistochemistry and the cytokeratin profile may aid the differentiation between TCC of the vagina and TCC of the urinary system, since vaginal $\mathrm{TCC}$ is $\mathrm{CK}^{+} / \mathrm{CK} 20^{-}$while bladder TCC is $\mathrm{CK} 7^{+} / \mathrm{CK} 20^{+}(16)$. Certain TCC patients are recommended for close follow-up examinations due to the increased risk of other urinary tract tumors (17).

Synchronous or metachronous vaginal metastasis of bladder TCC has been previously reported. However, the vagina is an uncommon site of metastasis for bladder cancer and other common malignancies $(18,19)$. Bladder TCC may metastasize to the vagina through various mechanisms, including through the lymphatic system or blood vessels, in ways that are similar to the metastasis of bladder cancer to the liver, lungs, brain, adrenals and bone (20). Another metastasis mechanism is associated with the retrograde venous blood flow from the bladder to the vagina, which is similar to the mechanism of penile metastases from bladder cancers $(21,22)$. However, vaginal metastasis may occur via another mechanism that involves the implantation of shed tumor cells into the vagina during micturition or transurethral resection, and probably possesses a better prognosis (23). This hypothesis is consistent with the hypothesis that metastases occurs on the sites of trocar placement, surgery scars, supra pubic catheter orifices and nephrostomy tracts, and emphasizes the importance of respecting surgical oncology principles (24-30). This hypothesis is based on the association of non-muscle invasive bladder and vaginal TCC with the same immunohistochemistry profile $(10,14,15,18,19,23,31-38)$. At present, 15 cases of vaginal TCC have been described in the literature, occurring at an average of 4.3 years subsequent to the initial diagnosis of bladder TCC. These patients are treated with a local excision of the metastases or a total hysterovaginectomy. The prognosis is good and recurrence is rare (39). However, another mechanism of pathogenesis may be responsible for the occurrence of vaginal tumors, which involves the direct invasion of a muscle-invasive bladder cancer that is misdiagnosed as a superficial tumor, and has progressed into the bladder wall with intact or minimal changes to the urothelium (40). The misdiagnosis may be partially due to $40 \%$ of non-muscle invasive tumors being understaged by an initial transurethral resection, which may be demonstrated by analyzing cystectomy specimens $(41,42)$. This highlights the importance of physical examinations and bimanual vaginal palpations in order to detect tumors in patients with non-muscle invasive bladder cancer. Second-look transurethral resection may also improve tumor staging, and is recommended for any patient with a $\mathrm{T} 1$ or high-grade tumor at the initial resection and in non-containing muscle specimens at pathology (43). Second-look transurethral resection may also be considered in cases where the urologist is unsure that the initial resection was complete, particularly in cases demonstrating extensive and multiple tumors (44). Inaccurate diagnosis and staging may lead to invasion of the vaginal wall by the direct extension of the tumor, and may adversely affect the survival of the patient.

Determining the pathogenesis of vaginal TCC that is associated with bladder TCC may affect the treatment and the prognosis of patients. Vaginal metastasis via the bloodstream is evidence of systemic disease that requires treatment with systemic therapy, and the prognosis is generally poor (19). Direct local invasion by a muscle-invasive bladder cancer may be surgically removed with the intent to cure. The role of adjuvant radiotherapy or chemotherapy in vaginal TCC is not clear. However, early diagnosis and accurate staging is mandatory in order to avoid vaginal invasion. The association between vaginal and non-muscle invasive TCC is complex. Primary vaginal TCC is an aggressive lesion that is usually invasive at the time of diagnosis. The therapy used for these lesions is similar to that used for conventional squamous cell carcinoma, and the prognosis is challenging to establish (19). Avoiding contamination of the vagina by irrigating fluid and urine during a transurethral resection is important in order to avoid malignant cells of the bladder seeding into the vaginal wall (23). 


\section{References}

1. American Cancer Society: Cancer Facts \& Figures 2014 American Cancer Society, Atlanta, GA, 2014.

2. Hayne D, Arya M, Quinn MJ, Babb PJ, Beacock CJ and Patel HR: Current trends in bladder cancer in England and Wales. J Urol 172: 1051-1055, 2004

3. American Cancer Society: What are the key statistics about bladder cancer? http://www.cancer.org/cancer/bladdercancer/detailedguide/bladder-cancer-key-statistics. Accessed 3 December 2014.

4. Salem $\mathrm{H}$ and El-Mazny A: Primary and secondary malignant involvement of gynaecological organs at radical cystectomy for bladder cancer: Review of literature and retrospective analysis of 360 cases. J Obstet Gynaecol 32: 590-593, 2012.

5. Djaladat H, Bruins HM, Miranda G, Cai J, Skinner EC and Daneshmand S: Reproductive organ involvement in female patients undergoing radical cystectomy for urothelial bladder cancer. J Urol 188: 2134-2138, 2012.

6. World Medical Association General Assembly: World Medical Association Declaration of Helsinki: Ethical principles for medical research involving human subjects (revised October 7 , 2000). HIV Clin Trials 2: 92-95, 2001.

7. Chen ME, Pisters LL, Malpica A, Pettaway CA and Dinney CP: Risk of urethral, vaginal and cervical involvement in patient undergoing radical cystectomy for bladder cancer: Results of a contemporary cystectomy series from M. D. Anderson Cancer Center. J Urol 157: 2120-2123, 1997.

8. Black PC, Dinney CPN, Brown GA, Kassouf W Siefker-Radtke AO, Munsell MF, Grossman HB and Kamat AM: The role of radical cystectomy in patients with clinical T4b bladder cancer. Urol Oncol 29: 157-161, 2011.

9. Reyes MC, ParkKJ, Lin O, Ioffe O, Isacson C, Soslow RA, Reuter VE and Fine SW: Urothelial carcinoma involving the gynecologic tract: A morphologic and immunohistochemical study of 6 cases. Am J Surg Pathol 36: 1058-1065, 2012.

10. Kaneko G, Kikuchi E, Hasegawa M, Miyajima A, Nakagawa K, Kameyama K and Oya M: Non-muscle invasive bladder cancer with concomitant vaginal urothelial carcinoma: A case report and review of the literature. Int J Clin Oncol 15: 626-630, 2010.

11. Patrelli TS, Silini EM, Berretta R, Thai E, Gizzo S Bacchi Modena A and Nardelli GB: Squamotransitional cell carcinoma of the vagina: diagnosis and clinical management: A literature review starting from a rare case report. Pathol Oncol Res POR 17: 149-153, 2011.

12. Gao Z, Bhuiya T and Falkowski O: Papillary squamotransitional cell carcinoma of the vagina: A case report and review of literature. J Obstet Gynaecol 25: 94-96, 2005.

13. Del Gobbo A, Patriarca C, Campo B and Giunta P: Primary urothelial cell carcinoma of the vagina. Int J Gynaecol Obstet 115: 292-293, 2011

14. Jendresen MB, Kvist E and Glenthøj A: Papillary transitional cell tumour in the vagina. Scand J Urol Nephrol 31: 107-108, 1997.

15. Singer G, Hohl MK, Hering F and Anabitarte M: Transitional cell carcinoma of the vagina with pagetoid spread pattern. Hum Pathol 29: 299-301, 1998.

16. Riedel I, Czernobilsky B, Lifschitz-Mercer B, Roth LM Wu XR, Sun TT and Moll R: Brenner tumors but not transitional cell carcinomas of the ovary show urothelial differentiation: Immunohistochemical staining of urothelial markers, including cytokeratins and uroplakins. Virchows Arch 438: 181-191, 2001.

17. Hermanova M, Vitezslav V, Husicka R, Neumanova R and Pacik D: Multicentric transitional cell carcinoma of the vagina and the ureter. Ann Diagn Pathol 12: 365-367, 2008.

18. Bulbul MA, Kaspar H, Nasr R and Khalil A: Urothelial carcinoma of the vagina six years following cystectomy for invasive cancer. A case report. Eur J Gynaecol Oncol 20: 233-234, 1999.

19. Okada Y, Nishiyama H, Nakashima M, Ito N, Kinoshita H, Yamamoto S, Kamoto T and Ogawa O: A case of vaginal metastasis of transitional cell carcinoma. Hinyokika Kiyo 50: 283-286, 2004 (In Japanese)

20. Wallmeroth A, Wagner U, Moch H, Gasser TC, Sauter G and Mihatsch MJ: Patterns of metastasis in muscle-invasive bladder cancer (pT2-4): An autopsy study on 367 patients. Urol Int 62 : $69-75,1999$
21. Bordeau KP and Lynch DF: Transitional cell carcinoma of the bladder metastatic to the penis. Urology 63: 981-983, 2004.

22. Berger AP, Rogatsch H, Hoeltl L, Steiner H, Bartsch G and Hobisch A: Late penile metastasis from primary bladder carcinoma. Urology 62: 145, 2003.

23. Ohgaki K, Horiuchi K, Oka F, Sato M and Nishimura T: Vaginal metastasis of urothelial carcinoma found incidentally during transurethral resection of a bladder tumor. J Nippon Med Sch 75: 312-315, 2008

24. Muntener M, Schaeffer EM, Romero FR, Nielsen ME, Allaf ME, Brito FAR, Pavlovich CP, Kavoussi LR and Jarrett TW: Incidence of local recurrence and port site metastasis after laparoscopic radical nephroureterectomy. Urology 70: 864-868, 2007.

25. Tsivian A and Sidi AA: Port site metastases in urological laparoscopic surgery. J Urol 169:1213-1218, 2003.

26. Otani M, Irie S and Tsuji Y: Port site metastasis after laparoscopic nephrectomy: Unsuspected transitional cell carcinoma within a tuberculous atrophic kidney. J Urol 162: 486-487, 1999.

27. Akman Y, Cam K, Kavak A and Alper M: Extensive cutaneous metastasis of transitional cell carcinoma of the bladder. Int J Urol 10: 103-104.

28. Kinouchi T, Hanafusa T, Kuroda M, Usami M and Kotake T: Ossified cystic metastasis of bladder tumor to abdominal wound after partial cystectomy. J Urol 153: 1049-1050, 1995.

29. Breul J, Block T, Breidenbach H and Hartung R: Implantation metastasis after a suprapubic catheter in a case of bladder cancer. Eur Urol 22: 86-88, 1992.

30. Sengupta S and Harewood L: Transitional cell carcinoma growing along an indwelling nephrostomy tube track. Br J Urol 82: 591, 1998.

31. Noordzij JW, Dabhoiwala NF, De Reijke TM and Van Den Tweel JG: Vulvar and vaginal implantation of transitional cell carcinoma of the urinary tract. Br J Urol 67:102-103, 1991.

32. Ralph DJ, Chapple CR and Evans JW: Seeding of transitional cell carcinoma within the vagina. Br J Urol 67: 660-661, 1991.

33. Kasai T, Moriyama K, Tsuji M, Uema K and Sakurai N: A case of vaginal implantation of transitional cell carcinoma of the bladder. Nippon Hinyokika Gakkai Zasshi 92: 538-541, 2001 (In Japanese).

34. Ogiso S, Maeno A, Yamashita M, Souma T, Nakamura K and Okuno H: Micturitional disturbance due to labial adhesion as a cause of vaginal implantation of bladder urothelial carcinoma. Int J Urol 13: 1454-1455, 2006.

35. Fetissof F, Haillot O, Lanson Y, Arbeille B and Lansac J: Papillary tumour of the vagina resembling transitional cell carcinoma. Pathol Res Pract 186: 358-364, 1990.

36. Bass PS, Birch B, Smart C, Theaker JM and Wells M: Low-grade transitional cell carcinoma of the vagina - an unusual cause of vaginal bleeding. Histopathology 24: 581-583, 1994.

37. Murai M, Nakamura H, Shinoda M, Ohashi M and Tazaki $H$ : Vaginal metastasis from transitional cell carcinoma of renal pelvis in horseshoe kidney. Urology 33: 477-480, 1989.

38. Kumar R, Kumar S and Hemal AK: Vaginal and omental metastasis from superficial bladder cancer. Urol Int 67: 117-118, 2001.

39. Mondaini N, Giubilei G, Raspollini MR, Crisci A and Orlando V: Recurrence of vaginal implantation of transitional cell carcinoma of the urinary tract. Gynecol Oncol 97: 669-670, 2005.

40. Amling CL: Diagnosis and management of superficial bladder cancer. Curr Probl Cancer 25: 219-278, 2001.

41. Chang WC, Chang YH and Pan CC: Prognostic significance in substaging ofT1 urinary bladder urothelial carcinoma on transurethral resection. Am J Surg Pathol 36: 454-461, 2012.

42. Dutta SC, Smith JA Jr, Shappell SB, Coffey CS, Chang SS and Cookson MS: Clinical under staging of high risk nonmuscle invasive urothelial carcinoma treated with radical cystectomy. J Urol 166: 490-493, 2001.

43. Babjuk M, Burger M, Zigeuner R, Shariat SF, van Rhijn BWG, Compérat E, Sylvester RJ, Kaasinen E, Böhle A, Palou Redorta J, et al; European Association of Urology: EAU guidelines on non-muscle-invasive urothelial carcinoma of the bladder: Update 2013. Eur Urol 64: 639-653, 2013.

44. Witjes JA, Compérat E, Cowan NC, De Santis M, Gakis G, Lebret T, Ribal MJ, Van der Heijden AG and Sherif A: EAU guidelines on muscle-invasive and metastatic bladder cancer: Summary of the 2013 guidelines. Eur Urol 65: 778-792, 2014. 